\title{
Apply GM(h,N) Model to Analyze the Influence Factor in Hybrid Vehicles
}

\author{
Han-Shen Chen ${ }^{1,2, *}$ \\ ${ }^{1}$ School of Diet and Restaurant Management, Chung Shan Medical University, Taichung City 402, Taiwan \\ ${ }^{2}$ Dept. of Medical Management, Chung Shan Medical University Hospital, Taichung City 402, Taiwan
}

Received: 3 Jul. 2013, Revised: 7 Nov. 2013, Accepted: 8 Nov. 2013

Published online: 1 May. 2014

\begin{abstract}
This research applied Fuzzy Delphi Analytic Hierarchy Process (FDAHP) to evaluate the critical success factors for New Product Development (NPD) by using a hybrid vehicle as an example. Grey Relational Analysis (GRA) is used to assess the level of gray relation among these factors, followed by empirical analysis to construct the NPD strategy. The empirical result illustrates that the indicators system can identify brand positioning and image moulding of product efficiency. The NPD strategy will be established by the revolutionary NPD model. In addition, this indicators system aids in identifying NPD targets and allocates strategic resources.
\end{abstract}

Keywords: Fuzzy Delphi Analytic Hierarchy Process (FDAHP), Grey Relational Analysis (GRA), New Product Development (NPD), indicators system; economical benefit, hybrid vehicle

\section{Introduction}

While every country is expanding its substitutive plans for vehicle fuel, the price of petroleum continues to increase and crude oil acquisitions have become more difficult. Therefore, hybrid and other energy saving vehicles such as those using bio-mass energy, diesel, electricity and hydrogen energy have gained popularity. Owing to the compatibility and complexity of novelty, petroleum and electric hybrid vehicles currently are a relatively mature product with a high compatibility of technology transformation. Petroleum and electric hybrid vehicles are supported by two power sources: an electric motor and a petroleum, diesel, or gas turbine engine. The theory is to utilize smaller and more efficient engines and electric motors to increase acceleration power and compensate for each other's disadvantages, while decreasing oil consumption and pollution. Yet, conventional petrol engines continue to dominate the industry. However, the power system anticipated to completely substitute it is the promising 'hydrogen' energy. The total investment in promoting hydrogen energy in Japan is estimated to reach US $\$ 4$ billion by 2020 to achieve a green hydrogen energy society. Germany, which has a strong green model, is leading the world in using hydrogen energy as a developmental trend for hydrogen and fuel cell vehicles.
Iceland, also known as the 'Green Energy Country', was the first to create a 'hydrogen economy' and hopes to use only hydrogen by 2050 , making it the major power source for all domestic transportation. In Taiwan, certain schools have partnered with industries to successfully develop a small hydrogen automobile that has passed its test drives. Nevertheless, many obstacles must be overcome to achieve broad popularization. Therefore, petroleum and electric hybrid vehicles continue to be the best current choice, transitioning from petroleum fuel vehicles to hydrogen vehicles. Currently, there are three models of petroleum-electric hybrids in Taiwan, the Toyota Prius, Ford Escape Hybrid and Lexus RX400h, all of which boast saving up to 50\% oil in general driving and $20 \%$ when driving at high speeds. However, their emissions of hydrocarbons and oxynitrides both exceed the environmental standard.

Current technology development evolves daily and the market environment changes rapidly along with diversification and dynamism of consumer demands, resulting in shorter product life cycles. Faced with such pressures, firms should continuously develop new products to strengthen their competitiveness and upgrade their product image. However, when developing new products to capture new territories, firms often ignore what Hise [1] described as specific design procedures and

\footnotetext{
*Corresponding author e-mail: allen9750@yahoo.com.tw
} 
an appropriate time interval for a complete new design development, which lowers the market success-rate of their New Product Development (NPD). Edgett et al. [2] investigated British and Japanese manufacturers, revealing failure rates for new products at $45.7 \%$ and $40.2 \%$, respectively. These rates have not changed significantly in the past 30 years.

Although faced with such arduous challenges and risks, it is still many firms' only solution for survival new design development. Balachandra and Friar [3] have proposed the contingency cube for NPD and R\&D projects, consisting of innovation (incremental/radical), market (new/existing) and technology (low tech/high tech) and yielded eight new product segmentations in three contextual dimensions. The authors noted the importance of dealing with the factors of these eight new product contexts (one for each combination of contextual variables) separately. Chiang [4] proposed an innovative design for a development model based on products' perceived value, technological innovation type and market segmentation to establish eight new product positioning models, each with key-positioning points emphasizing new products that require development and resource investment.

Although the NPD strategy is one of the most important elements of today's firms, manufacturers with limited resources often face resource distribution problems. Thus, from the firm's perspective NPD must be economically efficient and make optimum use of every available resource.

This study first establishes an index system to measure economic efficiency of NPD. We then utilize the Fuzzy Analytical Hierarchy Process Method (FAHPM) to establish quantification factors that can be used to create a mechanism to discuss the important factors' weight values. Thereafter, we utilize Grey Relational Analysis (GRA) to determine the key success factors of new design development, calculate each key factor's weight value and further combine the NPD model to analyze what manufactures should emphasize in development strategies related to the characteristics of new products. We then utilize the new design development's economic efficiency analysis, evaluation, and empirical study and have discussed improving the strategies of NPD economic efficiency and have offered a strategic proposal.

\section{Literature Review}

\subsection{Fuzzy Delphi analytic hierarchy process (FDAHP)}

Hsu [5] combined the Analytic Hierarchy Process (AHP) and the Fuzzy Delphi Method (FDM) to create a new group decision-making analysis method. This method integrates expert advice through the FDM to compensate for the traditional AHP method that could not consider fuzzy questions resulting from group opinions. In addition, the traditional AHP also needed to conduct investigations several times, which required more time and higher costs. Hsu's method, however, needs only one investigation to cover all experts' opinions, explained as follows

(1) Mean Value Generalization Modelling

Expert consensus refers to a functional form that can be determined by mutual consensus, which is also a type of mean value concept. Thus, we used mean value generalization modeling to explain different consensus functional forms; we then utilize triangular fuzzy numbers to determine different forms of consensus functions to establish a new FDM. The mean value generalization modeling is illustrated as follows

$$
h\left(a_{1}, a_{2}, \cdots, a_{n}\right)=\left[\frac{a_{1}^{a}+a_{2}^{a}+\cdots+a_{n}^{a}}{n}\right],
$$

Where $a$ represents the parameter of different mean value forms. If we give different values to a, we obtain the following

(a) When $a \rightarrow-\infty$, from formula(1)

$$
h_{-\infty}\left(a_{1}, a_{2}, \cdots, a_{n}\right)=\min \left(a_{1}, a_{2}, \cdots, a_{n}\right),
$$

We may know that the lower limit of the generalization mean value function is a minimum value. Thus, we can understand that the minimum value is a kind of minimummean-value functional form.

(b) When $a \rightarrow \infty$, from formula(1)

$$
h_{\infty}\left(a_{1}, a_{2}, \cdots, a_{n}\right)=\max \left(a_{1}, a_{2}, \cdots, a_{n}\right),
$$

We may know that the upper limit of the generalization mean value function is a maximum value. Thus, we can understand that the maximum value is a kind of maximummean-value functional form.

(c) When $a \rightarrow 0$, it is then a geometric mean value

$$
h_{0}\left(a_{1}, a_{2}, \cdots, a_{n}\right)=\left(a_{1}, a_{2}, \cdots, a_{n}\right)^{\frac{1}{n}},
$$

From explanations of mean value generalization modeling, we know that the minimum and maximum values are indicated separately in expert groups. A minimum and maximum mean value from expert appraisal is also a type of extreme expert mutual consensus modeling. Among expert consensus's, maximum and minimum values are several known and unknown forms of expert consensus functional values (such as geometric mean value, harmonic mean value, and arithmetic mean value). Therefore, we gave these different consensus functions different possibility grades (membership grades) in this analysis and thus, were able to establish a new FDM.

Saaty [6] has contended that if we use geometric mean value to express expert consensus, the effect will be better; thus, we utilize geometric mean value in most of our practical applications. Therefore, this analysis 


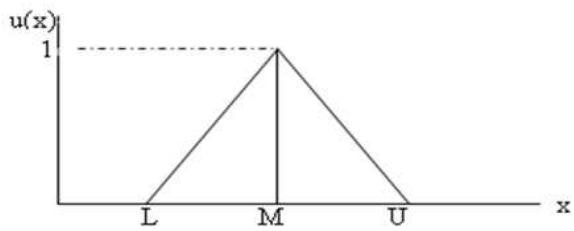

Fig. 1: Fuzzy Delphi Analytic Hierarchy Process Sketch Map. Source: Hsu [19]

adopted geometric mean value (representing the consensus of most experts) as a triangular fuzzy mode, i.e., when a membership grade equals a mean value, as illustrated in Figure 1. U is the expert consensus' upper limit (maximum value), L the expert consensus' lower limit (minimum value), and $\mathrm{M}$ is a geometric mean value representing most of the expert consensus. Therefore, the value within LU represents the different possibilities for consensus viewpoints.

(2) Establishment of Pair-Wise Comparison Fuzzy Value Every

pair-wise comparison matrix value represents a subjective viewpoint of each policy-maker. As it is a very fuzzy idea, we used the FDM to integrate expert ideas to represent the fuzzy consensus of group evaluators towards the degree of importance of two related standards. In accordance with the establishment of the FDM, we constructed a triangular fuzzy value as follows

$$
\widetilde{u}_{i f}=\left(\alpha_{i f}, \delta i_{i f}, \gamma_{i f}\right)
$$

$$
\left.\left.\alpha_{i j} \leq \delta i_{i j} \leq \gamma_{i f}\right) \text { and } \alpha_{i j}, \delta i_{i j}, \gamma_{i f}\right) \in[1 / 9,1] \bigcup[1,9]
$$

$$
\begin{aligned}
& \delta_{i j}=n \sqrt{\prod_{k=1}^{n} B_{i j k}}, \\
& \gamma_{i f}=\max \left(B_{i j k}\right),
\end{aligned}
$$

Where $B_{i j k}$ represents the opinions of expert $k$ on degree of importance of two standards $i$ and $j$. represents the opinions of expert $k$ on degree of importance of two standards $i$ and $j$.

(3) Fuzzy Pair-Wise Comparison Matrix

After we obtain the triangular fuzzy value of experts' opinions, we enter it into a pair-wise comparison matrix to manage standard judging and fuzzy consensus problems in evaluation. The organization of the FDM on the fuzzy pair-wise comparison matrix is as follows

$$
[\tilde{A}]=\left[\tilde{a_{i j}}\right]=\begin{gathered}
A 1 \\
A 2 \\
M \\
A n
\end{gathered}\left[\begin{array}{cccc}
A 1 & A 2 & \Lambda & A n \\
1 & \tilde{a}_{i j} & \Lambda & \left(a_{1 n}^{\alpha}\right)^{\lambda} \\
\tilde{a}_{21} & 1 & \Lambda & \left(a_{2 n}^{\alpha}\right)^{\lambda} \\
M & M & M & M \\
\tilde{a}_{n 1} & \tilde{a}_{n 2} & \Lambda & 1
\end{array}\right]
$$

Where $\tilde{a_{i j}}$ represents the relative degree of importance of the triangular fuzzy value on standard $A 1$ and standard $A 2\left[\tilde{a_{i j}}\right]$ is matrix of the triangular fuzzy value, using formulas $(5)-(8)$.

(4) Removing Fuzziness

From the pair-wise comparison matrix, obtained from the FDM, we used a fuzziness-removing method to produce a definite value list. This study adopted the methods of Hsu and Nai [7] and Lious and Wang [8], as listed in formula (10), which allowed us to express the 'fuzzy' consensus spirit. Through this method, we could show the degrees of strategy-makers' risk preference $(\alpha)$ and undertaking $(\lambda)$ to demonstrate the outcomes under different risks.

$$
\left(a_{i j}^{\alpha}\right)=\left[\lambda \cdot l_{i j}^{\alpha}+(1-\lambda) \cdot u_{i j}^{\alpha}\right], 0 \leq \lambda \leq 1,0 \leq \alpha \leq 1,
$$

Where $l_{i j}^{\alpha}$ represents the left point-a cut value $\alpha_{i j}$ and $u_{i j}^{\alpha}$ represents the right point- $a$ cut value $\alpha_{i j}$. Thus, we derive a single value pair-wise matrix, as illustrated in formula (11). represents the left point-a cut value - and represents the right point-a cut value. Thus, we derive a single value pair-wise matrix, as illustrated in formula (11).

$$
\left[\left(A^{\alpha}\right)^{\lambda}\right]=\left[\left(a_{i j}^{\alpha}\right)\right]=\begin{gathered}
A 1 \\
A 2 \\
M \\
A n
\end{gathered}\left[\begin{array}{cccc}
A 1 & A 2 & \Lambda & A n \\
1 & \left(a_{12}^{\alpha}\right)^{\lambda} & \Lambda & \left(a_{1 n}^{\alpha}\right)^{\lambda} \\
\left(a_{21}^{\alpha}\right)^{\lambda} & 1 & \Lambda & \left(a_{2 n}^{\alpha}\right)^{\lambda} \\
M & M & M & M \\
\left(a_{n 1}^{\alpha}\right)^{\lambda} & \left(a_{n 2}^{\alpha}\right)^{\lambda} & \Lambda & 1
\end{array}\right]
$$

(5) Calculation of Characteristic Value and Vector

After obtaining the single value pair-wise comparison matrix, we use the characteristic vector method to find the weight. If $\bar{\lambda}$ represents the characteristic value of a single value pair-wise comparison matrix $\left(A^{a}\right)^{\lambda}$ then $w$ is the characteristic vector of $\left(A^{a}\right)^{\lambda}$ then $w$ :

$$
\left.A^{a}\right)^{\lambda} \cdot W=\lambda \cdot W
$$

$$
\left.\left(A^{a}\right)^{\lambda}-\bar{\lambda}\right) \cdot W=0,0 \leq \alpha \leq 1 ; 0 \leq \lambda \leq 1,
$$

In summary, the study applied the FAHPM to evaluate an NPD model. The purpose was to use a hierarchy analysis method to establish a mutual hierarchy-order relationship using new hybrid vehicle products to evaluate each important factor. We utilized an expert questionnaire design and an analytical process to obtain important comparison values and later utilized the FDM's calculation formulae to determine the fuzzy weight value of each factor. With help from specialized experts' perceptions and quantification appraisal tools, we hoped to perform a key factor grading of new hybrid vehicle products. 


\subsection{Grey Relational Analysis}

Proposed by Professor Julong Deng in 1982, the gray theory has been applied extensively to different fields of management science. When the system model is not clear and the information is incomplete, the gray theory engages the system in relational analysis and model construction. Through prediction and decision-making methods, it explores and describes the condition of the system and can deal effectively with the uncertainty of issues and the incompleteness of data [9]. Unremitting hard work and pioneering scholarships have improved the gray system theory, and it has been successfully applied in dozens of areas, including fields of electronic, electrical, mechanical, aerospace, civil engineering, water conservancy, transportation, construction, legal, medical, management, and education $[10,11,12,13,14]$. The above research results illustrate that the gray system theory comprises highly reliable, easy to understand, computational analysis tools. Among them, GRA is one of six categories of research methods in the gray theory; its main function is to analyze a discrete sequence of a calculated correlation measure.

The major GRA steps are as follows [15]

(1) Step 1: Data Processing

Suppose there is a sequence

$$
x_{i}=\left(x_{i}(1), \cdots, x_{i}(k)\right) \in X,
$$

Where $i=0,1,2, \cdots, m ; k=1,2,3, \cdots, n \in N$,

Before attempting GRA of a series group, all series must meet the following three conditions:

(a) Non-dimension: Irrespective of the gauging unit of the factor must be turned into a nondimension type.

(b) Scaling: The values $x_{i}(k)$ of all series $x_{i}$ must either be of the same grade, or the grade difference cannot be greater than 2 .

(c) Polarization: The factor description-type of the series must be of the same direction, i.e., the series $x_{i}$ has comparability.

In order to meet the three GRA comparability requirements, the original series must undergo some preprocessing, which is called gray relational generating.

(2) Step 2: Finalization of the Analytical Series

In gray relational space $\{P(X) ; \Gamma\}$ there is a series $x_{i}=$ $\left(x_{i}(1), \cdots, x_{i}(k)\right) \in X$

Where $i=0,1,2, \cdots, m ; k=1,2,3, \cdots, n \in N$,

Namely, $X_{0}=\left(x_{0}(1), \cdots, x_{0}(k)\right)$

$X_{1}=\left(x_{1}(1), \cdots, x_{1}(k)\right)$

$X_{2}=\left(x_{2}(1), \cdots, x_{2}(k)\right)$

$\vdots=\vdots$

$X_{m}=\left(x_{m}(1), \cdots, x_{m}(k)\right)$

The gray relational coefficient $\gamma\left(x_{i}(k), x_{i}(k)\right)$ of local or global Grey Relational Measurement (GRM) is defined as follows: (a) Localized: When there is only one series $x_{0}(k)$ as the reference series, and others are comparison series, the gray relational coefficient is defined as follows

$$
\gamma\left(x_{i}(k), x_{i}(k)\right)=\frac{\Delta \min \cdot+\varsigma \Delta \max .}{\Delta_{0 i}(k)+\varsigma \Delta \max },
$$

Where $i=1,2,3, \cdots, m, k=1,2,3, \cdots, n \in j ; x_{0}$ is the reference series, and $x_{i}$ is a specific comparison series.

$\Delta_{0 i}=\left\|x_{o}(k)-x_{i}(k)\right\|$ (The absolute value of the difference $K$ between $x_{0}$ and $x_{i}$ )

$\Delta \min =\forall j^{\text {min }} \in i \forall k^{\text {min }}\left\|x_{o}(k)-x_{i}(k)\right\|$

$\Delta \max =\forall j^{\max } \in i \forall k^{\max }\left\|x_{o}(k)-x_{i}(k)\right\|$

$\varsigma$ :Distinguishing Coefficient: $\varsigma \in[0,1]$ (the value can be adjusted according to actual requirements)

(b) Global: When any series $x_{i}(k)$ can be the reference series, and other series are comparison series, the gray relational coefficient is defined as follows

$$
\gamma\left(x_{i}(k), x_{i}(k)\right)=\frac{\Delta \min \cdot+\varsigma \Delta \max .}{\Delta_{0 i}(k)+\varsigma \Delta \max },
$$

$\Delta_{i j}=\left\|x_{i}(k)-x_{j}(k)\right\|$ (The absolute value of the difference $K$ between $x_{i} 4$ and $x_{i}$

$\Delta \min =\forall j^{\min } \in i \forall k^{\min }\left\|x_{o}(k)-x_{i}(k)\right\|$

$\Delta \max =\forall j^{\max } \in i \forall k^{\max }\left\|x_{o}(k)-x_{i}(k)\right\|$

$\varsigma$ :Distinguishing Coefficient: $\varsigma \in[0,1]$ (the value can be adjusted according to actual requirements)

(3) Step 3: Calculating the gray relational coefficient

Under the condition of $\Delta_{0 i}(k)=\left|x_{0}(k)-x_{i}(k)\right|$ (the magnitude of the difference series is determined.)

Where $i=1,2,7, k=$ (numberof samples)

In order to determine the maximum and minimum difference of the two poles: Utilize the formula.

$$
\begin{gathered}
\Delta \text { min }=\forall j^{\text {min }} \in i \forall k^{\text {min }}\left\|x_{o}(k)-x_{i}(k)\right\|, \\
\Delta \max =\forall j^{\text {max }} \in i \forall k^{\text {max }}\left\|x_{o}(k)-x_{i}(k)\right\|,
\end{gathered}
$$

To calculate the gray relational coefficient: Insert the maximum and minimum difference into the formula.

$$
\gamma\left(x_{i}(k), x_{i}(k)\right)=\frac{\Delta \min \cdot+\varsigma \Delta \max .}{\Delta_{0 i}(k)+\varsigma \Delta \max },
$$

In the gray relational coefficient, the main function of the distinguishing coefficient $(\varsigma)$ is to serve as a contrast between the background and the object measured. The value can be adjusted according to actual requirements. In general, the value of the distinguishing coefficient is normally set at 0.5 . Yet in order to magnify the differentiation, it can be adjusted in accordance with the actual requirements. Changing the value of the distinguishing coefficient $(\varsigma)$ will only change the relative value of the magnitude; it will not affect the ranking of the gray relational grade. In this study the value of the distinguishing coefficient is set at 0.5 .

(4) Step 4: Calculating the gray relational grade

The space that is formed from the factor space and comparability is called the gray relational space, which is 
expressed by $\{P(X) ; \Gamma\}$, in which $(\{P(X)\}$ is the subject and $\Gamma$ is the measure. To $\{P(X) ; \Gamma\}$ there are four axioms:

(a) Normative

$$
0<\gamma\left(x_{i}, x_{j}\right) \leq 1 \forall i, \forall j
$$

When $\gamma\left(x_{i}, x_{j}\right)=1$, it is completely correlated. When $\gamma\left(x_{i}, x_{j}\right)=0$, it is not correlated.

(b) Duality: When the series has only two groups

$$
\gamma\left(x_{i}, x_{j}\right)=\gamma\left(x_{j}, x_{i}\right)
$$

(c) Entirety: When the series has three or more groups

$$
\gamma\left(x_{i}, x_{j}\right) \neq_{\text {often }} \gamma\left(x_{j}, x_{i}\right)
$$

(d) Accessibility

$\left|x_{i}, x_{j}\right|$ is the main control item of the entire $\gamma\left(x_{i}(k), x_{j}(k)\right)$; therefore, the magnitude of the gray relational grade must be related to this items

If in the gray relational space we can find a function $\gamma\left(x_{i}, x_{j}\right) \in \Gamma$ that satisfies all four axioms above, it is called $\gamma\left(x_{i}, x_{j}\right)$, which is the gray relational grade of the gray relational space.

After the gray relational coefficient is obtained, we can determine the mean value of the gray relational coefficient as the gray relational grade.

$$
\gamma\left(x_{i}, x_{j}\right)=\frac{1}{n} \sum_{k=1}^{n} \gamma\left(x_{j}, x_{i}\right),
$$

(5) Step 5: Arraying the gray relational ordinal

According to the definition of the gray theory, the traditional gray relational is employed to express the relationship between two series using qualitative analysis. The most important information, therefore, is the ranking of relational degrees. The gray relational data of $\mathrm{m}$ number of comparison series against the same reference series $x_{0}$ are ranked, and the ranking is called the gray relational ordinal.

In reference series $x_{0}$ and comparison series $x_{i}$

$x_{0}=\left(x_{0}(k)\right), x_{i}=\left(x_{i}(k)\right), k=1,2,3 \cdots, n, i=$ $1,2,3 \cdots, m$, if $\gamma\left(x_{0}, x_{i}\right) \geq \gamma\left(x_{0}, x_{j}\right)$

We then say the relational degree of $x_{i}$ and $x_{0}$ is greater than the relational degree of $x_{j}$ and $x_{0}$. Expressed through $x_{i}>x_{j}$, it is also called the gray relational ordinal $x_{i}$ of and $x_{j}$.

This research utilized GRA to separate and determine the quadrant to which new products belong, based on each aspect, using the discriminative value 0.6 to obtain an appropriate NPD strategy analysis. We then incorporate Chiang's NPD strategy [4] and create a set of NPD modes to provide domestic hybrid vehicle manufacturers with a new resource for determining the appropriate direction of product development strategy.

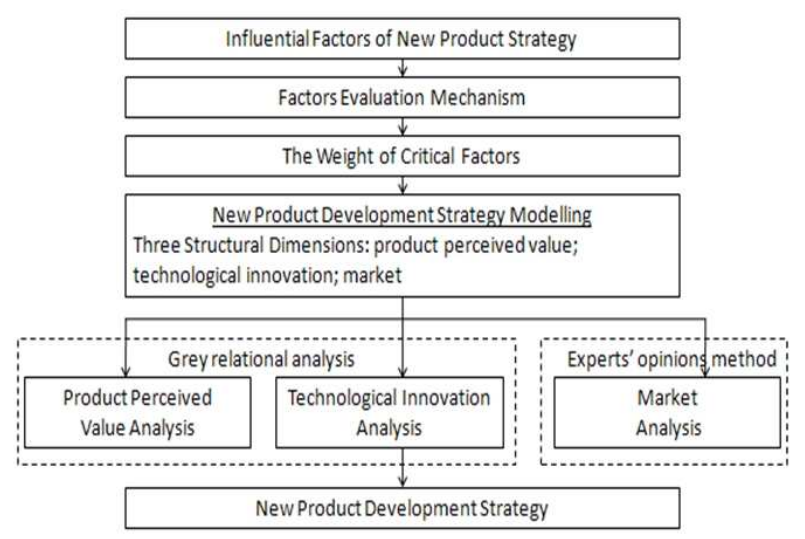

Fig. 2: Research framework

\section{Research Design and Method}

\subsection{Research framework}

This research adopted a synthetic analysis from experts' opinions to determine the product innovation factor construction of the hybrid vehicle industry. Later, we utilized the FAHPM to calculate factor weight. Thereafter, using three structural dimensions of innovative NPD modeling [4] we utilized GRA to determine the quadrant to which new products belonged for each aspect to obtain an appropriate NPD strategy. The objective of this study is to develop a set of quantifications for NPD strategy modeling to provide manufacturers a basis to establish an innovative product strategy. The research framework is illustrated in Figure 2.

\subsection{New product development economic efficiency indicators}

NPD economic efficiency indicators are illustrated in Table 1.

\section{Empirical Research}

\subsection{Forecasting new product development economic efficiency}

According to the confirmed forecast goal and regarding influential factors of NPD economic efficiency, this study utilized the gray system theory in forecasting NPD economic efficiency. Next we processed DPS statistics to obtain a relational degree between each factor and weight value (see Table 2).

According to relational degree requirements, if the relational degree exceeds 0.6 it can be used to establish a model, 
Table 1 NPD economic efficiency indicators

\begin{tabular}{lllll}
\hline Objective level & Territory level & Index Level & Definition & Formula \\
\hline & New product & Based on the time needed for \\
average development & former product development; \\
& cycle(A11) & $\begin{array}{l}\text { used to calculate product } \\
\text { development }\end{array}$ & $P_{n}=\frac{\sum_{i=1}^{n} P_{i}}{N}$ \\
& &
\end{tabular}

Time Index (A1

New product investment average payout cycle (A12

Labor force structural level (A21)

Efficiency

Index (A2) equipment capability (A22)

Total staff productivity (A23)

NPD

Economic

Efficiency

$\operatorname{Index}(\mathrm{F})$
Based on previous product development investment amount; used to calculate new product investment average payout period

Including two aspects of labor force average, education level and technical level, it can be divided into two classifications: operator and specialist technician

Used to reflect whether current equipment can adapt to the needs of NPD

Based on manufactured value; used to calculate the product quantity of each worker within a unit of time

Aimed at items involved with information technology, to give them a fixed score separately; it will then be able to obtain the company's current information technology's respect degree

The benefits of product service perceived by customers after

Customer value degree (A31)

Product technical level (A32)

Value Index

(A3)

New product capital profit rate (A33)

New product value rate (A34) weighing the pay-out cost from obtaining the product service, and the overall evaluation on product service

Besides personal technological the enterprise still needs to improvement, including product

Used to reflect the obtainable profit for each $\$ 100$ in floating capital taken up by new product developed by the enterprise

Used to reflect the enterprise's technology progress and
New product average investment payout period $=($ New product total investment amount)/(New product yearly profit amount + yearly depreciation amount)

Labor force average education level $=\sum$ (certain class group education level factor $\mathrm{x}$ that group people number $) / \Sigma$ number of people in each group Labor force technical level $=\sum$ (certain class group technical level factor $\times$ that group people number) $/ \sum$ the number of people in the group

Technical equipment capability $=\sum$ (each class group people number $\times$ that level/class score) $/ \Sigma$ each level/class/group people number

Total people labor production rate $=$ (Report period cumulative new product increased value $(\$ 10,000) /$ Report period total worker average people number) $100 \%$

Information technology important degree $=\sum$ (score taken up by each item $\times$ that item's people number) $/ \sum$ each development capability
Customer value degree $=\sum$ (score taken up by each level $\times$ that level's people number) $/ \Sigma$ each level's people number

innovation to raise the technical standard, strengthen product management and quality loss ratio and a single inspection pass rate

New product capital profit amount created by new product/Average amount of floating capital taken up by new product) $\times 100 \%$

New product output value rate $=$ (Report period new product value ( $\$ 10,000$, unchanged value)/Report period industrial total product value $(\$ 10,000$, unchanged value $) \times 100 \%$ 
Table 2 Relational degree and weight value of each factor

\begin{tabular}{lll}
\hline Factor & Relational degree & Weight \\
\hline New product average development cycle & 0.7856 & 0.1563 \\
New product investment average payout cycle & 0.5862 & 0.1232 \\
Labor force structural level & 0.5638 & 0.1327 \\
Technical equipment capability & 0.5835 & 0.1224 \\
Total staff productivity & 0.6846 & 0.1657 \\
Information technology respect degree & 0.7673 & 0.1382 \\
Customer value degree & 0.8211 & 0.1585 \\
Product technical level & 0.7978 & 0.1412 \\
New product capital profit rate & 0.596 & 0.135 \\
New product value rate & 0.6124 & 0.1326 \\
\hline
\end{tabular}

i.e., if hybrid vehicle company A can acquire several indexes for its new products, it will be able to utilize them to predict those products' economic efficiency. Major influential factors include the average product development cycle, staff labor productivity, information technology level, customer value, product technical standards, and new product value rate. Table 2 reveals the experts' consensus on customer value. With customers' approval, economic efficiency is likely to improve. Next, we established a dynamic model $G M(1,7)$ and used multidimensional statistical software DPS to compute data. Table 3 illustrates the system operation result. The two indexes on customer value and product technical standard were high, indicating that these two items had a large effect on NPD. The parameter values of staff labor production rate and information technology level were negative, but their relational degree was higher, suggesting that we should have high expectations for future NPD.

The differences in data dimensional units from the original model caused much difficulty in obtaining accurate results. Therefore, it was necessary to standardize the original data. The parameter standardization is expressed as follows:

$$
X_{j D}=\frac{X_{j}-X_{\text {jmin }}}{X_{\text {jmax }}-X_{\text {jmin }}}\left(0 \leq X_{j D} \leq 1\right)
$$

Table 4 illustrates the post-recalculation result. After standardizing the original data and removing the influential non-unified dimension, the correlations between factors are clearer. When the deviation values were all greater than 0 and lesser than 0.315 , the model depicted good stability. From this output result, we understand that the absolute and relative error of the data has decreased and that the model's precision has significantly increased. This also demonstrated that original data standardization is necessary.

Through our analysis of an actual example, we reached the following conclusions: (1) using gray theory to predict the result is credible; (2) compared with other methods, the advantage of using $(1, N)$ in modeling is needed for less information than the four pieces normally required; (3) during modeling the selection of influential factors is very important and the influential factors must be representative; (4) the precision is high for this law in modeling economic efficiency, so it has widespread application.

\subsection{Establishing a fuzzy relationship matrix for synthetic evaluation}

(1) To perform a second hierarchy evaluation on every element of each $u_{i}$
We allowed experts to evaluate each element of the index system. In using the statistics, we followed a unified standard scale (good, better, general, bad, and worse) to determine the qualitative opinions as quantification evaluation values. The five levels of qualitative opinions' corresponding evaluation values were $1,0.8,0.6,0.4$, and 0.2 , respectively. The final score of each appraisal attribute was the sum of all experts' evaluation (Table 5).

According to this theory, we may obtain the fuzzy relationship matrix.

$$
\begin{aligned}
& R_{1}=\left|\begin{array}{ccccc}
0.22 & 0.52 & .026 & 0 & 0 \\
0 & 0.73 & 0.27 & 0 & 0
\end{array}\right| \\
& R_{2}=\left|\begin{array}{ccccc}
0 & 0.63 & .016 & 0.21 & 0 \\
0 & 0.57 & 0.43 & 0 & 0 \\
0.38 & 0.62 & 0 & 0 & 0
\end{array}\right| \\
& R_{2}=\left|\begin{array}{ccccc}
0.71 & 0.29 & .0 & 0 & 0 \\
0 & 0.333 & 0.333 & 0.33 & 0 \\
0.42 & 0.33 & 0.25 & 0 & 0 \\
0 & 0.24 & 0.52 & 0.24 & 0
\end{array}\right|
\end{aligned}
$$

Then the second level synthetic evaluation is

$B_{1}=A_{1} R_{1}=(0.120 .620 .2600)$

$B_{2}=A_{2} R_{2}=(0.080 .600 .260 .060)$

$\left.B_{3}=A_{3} R_{3}=0.340 .300 .240 .120\right)$

(2) The first hierarchy synthetic evaluation

We assumed subset $u_{i}$ as the first hierarchy's first element, and the second hierarchy's synthetic evaluation vector $B_{i}$ as the $\mathrm{U}$ single factor evaluation. Using this calculation on the first hierarchy weight vector $A=(0.2850 .2270 .488)$ and the evaluation on sub-factor $B^{\prime}=\left|\begin{array}{c}B_{1} \\ B_{2} \\ B_{3}\end{array}\right|$, we obtained the first hierarchy's synthetic evaluation as follows:

$$
B^{\prime}=A \bullet R^{\prime}=(0.220 .460 .250 .070)
$$

(3) Evaluation result

According to the weighted mean principle, we set the corresponding values of judgment subset $V$ as 100, 90, 70, 50 and 20 and set $k=1$. The evaluation result is

$$
C=(0.220 .460 .250 .070)=\left|\begin{array}{c}
100 \\
90 \\
70 \\
50 \\
20
\end{array}\right|=84.4
$$

We learn from this analysis that the synthetic evaluation of an NPD's economic efficiency is better because the new product can respond to customer demand, demonstrate customer value during the development process and exhibit broad market 


\begin{tabular}{|c|c|c|c|c|c|c|c|}
\hline Factor & $\begin{array}{l}\text { NPD economy } \\
\text { efficiency }\end{array}$ & $\begin{array}{l}\text { New product } \\
\text { average } \\
\text { development } \\
\text { cycle }\end{array}$ & $\begin{array}{l}\text { Total staff } \\
\text { productivity }\end{array}$ & $\begin{array}{l}\text { Information } \\
\text { technology } \\
\text { respect } \\
\text { degree }\end{array}$ & $\begin{array}{l}\text { Customer } \\
\text { value } \\
\text { degree }\end{array}$ & $\begin{array}{l}\text { Product } \\
\text { technical } \\
\text { level }\end{array}$ & $\begin{array}{l}\text { New } \\
\text { product } \\
\text { value rate }\end{array}$ \\
\hline $\begin{array}{l}\text { Coordination } \\
\text { coefficient }\end{array}$ & 1.8967 & 3.246 & -1.722 & -0.656 & 23.565 & 15.342 & 2.443 \\
\hline
\end{tabular}

Table 4 The $G M(1,7)$ model output result after original data standardization

\begin{tabular}{lllll}
\hline & $x^{0}$ & Fitted Value & Absolute error & Relative error \\
\hline$x(1)$ & 0.736 & 0.813 & 0.076 & 0.103 \\
$x(2)$ & 2.036 & 1.932 & -0.104 & -0.051 \\
$x(3)$ & 1.585 & 1.324 & -0.261 & -0.165 \\
$x(4)$ & 1.025 & 0.852 & -0.173 & -0.169 \\
$x(5)$ & 2.354 & 2.569 & 0.315 & 0.134 \\
$x(6)$ & 0.998 & 1.137 & 0.139 & 0.139 \\
$x(7)$ & 0.896 & 0.766 & -0.13 & -0.145 \\
$x(8)$ & 1.223 & 1.255 & 0.032 & 0.026 \\
$x(9)$ & 1.556 & 1.312 & 0.244 & 0.157 \\
$x(10)$ & 0.858 & 0.986 & 0.128 & 0.149 \\
$x(11)$ & 0.765 & 0.886 & 0.121 & 0.158 \\
$x(12)$ & 1.356 & 1.123 & -0.233 & -0.171 \\
$x(13)$ & 0.798 & 0.865 & 0.067 & 0.084 \\
$x(14)$ & 0.932 & 0.988 & 0.056 & 0.06 \\
$x(15)$ & 1.654 & 1.485 & -0.169 & -0.102 \\
\hline
\end{tabular}

Table 4 The $G M(1,7)$ model output result after original data standardization

\begin{tabular}{llllll}
\hline Indicators & Good & Better & $\begin{array}{l}\text { Evaluation } \\
\text { General }\end{array}$ & Bad & Worse \\
\hline New product average development cycle & 1 & 2.4 & 1.2 & 0 & 0 \\
New product investment average payout cycle & 0 & 3.2 & 1.2 & 0 & 0 \\
Labour force structural level & 0 & 2.4 & 0.6 & 0.8 & 0 \\
Technical equipment capability & 0 & 2.4 & 1.8 & 0 & 0 \\
Total staff productivity & 2 & 3.2 & 0 & 0 & 0 \\
Customer value degree & 4 & 1.6 & 0 & 0 & 0 \\
Product technical level & 0 & 0.8 & 0.8 & 0.8 & 0 \\
New product capital profit rate & 2 & 1.6 & 1.2 & 0 & 0 \\
New product value rate & 0 & 0.8 & 1.8 & 0.8 & 0 \\
\hline
\end{tabular}

potential. Thus, the enterprise should accelerate the development process to seize the market initiative.

\section{Conclusions and Recommendations}

By using the FAHPM and GRA, this study uses quantification and materialization methods to develop an innovative NPD model for product positioning and to identify an appropriate NPD strategy. The model may be used to provide a robust NPD model for NPD and product innovations. The study reached three conclusions:

(1) Structural confirmation of product innovation factors

Through interviewing experts, this study established the production innovation factors of the hybrid vehicle industry's products, generating a complete evaluation of the industry's future product innovation and development strategy. The study offers a strong, reliable appraisal structure.
(2) Quantification tool of NPD strategy modeling

This study combined the FAHPM and GRA to conduct an analysis by coordinating all aspects of NPD modeling. The model's strength is its ability to identify and quantify the product's key innovation factors and place the product in the correct strategy quadrant.

(3) Selection basis of product innovative factors

After interviewing experts and reviewing related literature, we sought the most important production innovation factors. After analyzing them, we could schedule the key points during new product innovation processing, evaluate the factor index weight based on each structural aspect and select the key points of development. Next, to address limited company resources and the innovation budget we can judge the weight of each evaluation factor to adjust the resource investment. This will provide companies with the necessary groundwork to select development factors when planning NPD. 
The authors are grateful to the anonymous referee for a careful checking of the details and for helpful comments that improved this paper.

\section{References}

[1] R. T. Hise, L. A. O’Neal, A. Parasuranman, J.U. McNeal, Journal of Product Innovation Management, 6, 43-50 (1989).

[2] S. Edgett, D. Shipley, G. Forbes, Journal of Product Innovation Management, 9, 3-10 (1992).

[3] R. Balachandra and J.H. Friar, IEEE Transactions on Engineering Management, 44, 276-287 (1997).

[4] W. L. Chiang, The study of a successful new product development model. Unpublished master's thesis, National Chiao Tung University, Hsinchu, Taiwan, (2001).

[5] T. H. Hsu, Journal of the Chinese Fuzzy Systems Association, 4, 59-72 (1998).

[6] T. L. Saaty, The analytic hierarchy process, New York: McGraw-Hill International Book Company, (1980).

[7] T. H. Hsu and S. H. Nian, Journal of the Chinese Institute of Transportation, 10, 79-96 (1997).

[8] T. S. Lious and M. J. J. Wang, Fuzzy Sets \& Systems, 50, 247-255 (1992).

[9] J. Deng, Grey System Theory and Applications, Taipei: Gau Lih Book Co. Ltd., (2000).

[10] S. O. Chen, C. C. Huang, M. L. You, C. Y. Kung, Proceedings of 2007 Frontiers in the convergence of bioscience and information technologies conference, 1-6 (2007).

[11] C. Y. Kung, C. K. Lee, C. M. Wang, T. M. Yan, Journal of Grey System, 10, 97-104 (2007).

[12] C. Y. Kung and K. L. Wen, Journal of Decision support Systems, 43, 842-852 (2007).

[13] C. Y. Kung, T. M. Yan, C. C. Huang, Proceedings of 2007 International Conference on Intelligent \& Advanced Systems Conference, 1-4 (2007).

[14] C. Y. Kung, T. M. Yan, C. C. Huang, Proceedings of IEEE International Conference on Systems, Man, and Cybernetics, 2866-2871 (2008).

[15] W. C. Chang, K. L. Wen, T. C. Chang, Application on grey relation model, Taipei: Gau Lih Book Co. Ltd., (2000).

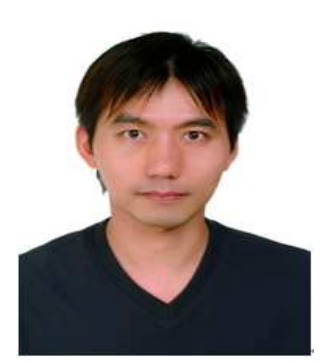

Han-Shen Chen is currently an Associate Professor of the School of Diet and Restaurant Management, Chung Shan Medical University, Taichung City, Taiwan. He obtained his Doctorate degree at the National Cheng Kung University in 2008 in the study of the resource engineering. His research interests are environmental and natural resource economics, recreation and tourism, and quantitative statistical analysis. 